\title{
Consumo de suplementos alimentares por participantes de atividade física em
}

\section{academias}

\author{
Consumption of dietary supplements by physical activity participants in gyms \\ Consumo de complementos alimenticios por parte de participantes de actividad física en gimnasios
}

Recebido: 29/07/2021 | Revisado: 07/08/2021 | Aceito: 09/08/2021 | Publicado: 14/08/2021

\author{
Márcio da Conceição Vieira Júnior \\ ORCID: https://orcid.org/0000-0001-6839-4251 \\ Prefeitura Municipal de Datas-Minas Gerais, Brasil \\ E-mail: junior_edfis@yahoo.com.br \\ Rosana Passos Cambraia \\ ORCID: https://orcid.org/0000-0003-2555-5830 \\ Universidade Federal dos Vales do Jequitinhonha e Mucuri, Brasil \\ E-mail: rosa.cambraia@ufvjm.edu.br \\ Assis do Carmo Pereira Júnior \\ ORCID: https://orcid.org/0000-0003-2609-4626 \\ Universidade Federal dos Vales do Jequitinhonha e Mucuri, Brasil \\ E-mail: assisdocarmo@ufvjm.edu.br
}

\begin{abstract}
Resumo
O objetivo deste estudo foi verificar o consumo de suplementos alimentares por frequentadores de academias. Para tanto, participaram 430 praticantes de atividades físicas de ambos os sexos, com idade entre 18 a 79 anos, frequentadores de todas as academias de um município de Minas Gerais. A coleta de dados ocorreu com a aplicação de questionários padronizados. A tabulação de dados foi realizada com o Epi Info 7.2 e para a análise dos dados foram utilizados os programas, Excel ${ }^{\circledR} 2010$ e BioEstat ${ }^{\circledR}$ 5.3. Verificou-se que 50,93\% dos praticantes usavam suplementos nutricionais, sendo predominante o consumo entre os homens $(66,21 \%)$. Entre os usuários, $80,37 \%$ disseram ter conhecimento sobre suplementos alimentares. Os suplementos mais utilizados entre os homens foram aqueles ricos em proteínas $(59,62 \%)$ e creatina $(35,68 \%)$ e entre as mulheres foram as proteínas $(25,81 \%)$ e os naturais fitoterápicos $(13,36 \%)$. A maioria $(70 \%)$ dos praticantes relatou consumir suplementos sem orientação de um profissional especializado. Conclui-se que é elevado o consumo de suplementos alimentares, sem orientação profissional adequada, por frequentadores de academias. Sendo assim, percebemos como indispensável a atuação de nutricionistas nas academias de ginástica, trabalhando juntamente com os profissionais da Educação Física, pois são habilitados para prescreverem e acompanharem o uso dos suplementos, tornando assim o consumo eficaz e seguro para os praticantes de atividade física.
\end{abstract}

Palavras-chave: Academia de ginástica; Exercício físico; Substâncias para melhoria do desempenho; Suplementos nutrocionais.

\begin{abstract}
The aim of this study was to verify the consumption of dietary supplements by gymgoers. To this end, 430 practitioners of physical activities of both genders, aged between 18 and 79 years old, attending all gyms in a municipality in Minas Gerais, participated. Data collection took place through the application of standardized questionnaires. Data tabulation was performed with Epi Info 7.2 and for data analysis the programs Excel® 2010 and BioEstat ${ }^{\circledR} 5.3$ were used. It was found that $50.93 \%$ of practitioners used nutritional supplements, predominantly consumption among men (66.21\%). Among users, $80.37 \%$ said they knew about food supplements. The most used supplements among men were those rich in proteins $(59.62 \%)$ and creatine $(35.68 \%)$ and among women were proteins $(25.81 \%)$ and natural herbal medicines $(13.36 \%)$. The majority $(70 \%)$ of practitioners reported consuming supplements without guidance from a specialized professional. It is concluded that the consumption of food supplements is high, without adequate professional guidance, by gymgoers. Therefore, we see as essential the role of nutritionists in gyms, working together with Physical Education professionals, as they are qualified to prescribe and monitor the use of supplements, thus making their consumption effective and safe for practitioners of physical activity.
\end{abstract}

Keywords: Fitness centers; Exercise; Performance-enhancing substances; Dietary supplements.

\section{Resumen}

El objetivo de este estudio fue verificar el consumo de suplementos dietéticos por parte de los asistentes al gimnasio. Para ello participaron 430 practicantes de actividades físicas de ambos sexos, con edades comprendidas entre los 18 y 79 años, que asisten a todos los gimnasios de una ciudad de Minas Gerais. La recolección de datos se realizó mediante 
la aplicación de cuestionarios estandarizados. La tabulación de datos se realizó con Epi Info 7.2 y para el análisis de datos se utilizaron los programas Excel ${ }^{\circledR} 2010$ y BioEstat ${ }^{\circledR}$ 5.3. Se encontró que el 50,93\% de los practicantes utilizaba complementos nutricionales, predominantemente el consumo entre los hombres (66,21\%). Entre los usuarios, el 80,37\% dijo tener conocimientos sobre complementos alimenticios. Los suplementos más utilizados entre los hombres fueron los ricos en proteínas $(59,62 \%)$ y creatina $(35,68 \%)$ y entre las mujeres fueron las proteínas $(25,81 \%)$ y los medicamentos naturales a base de hierbas $(13,36 \%)$. La mayoría (70\%) de los médicos informaron consumir suplementos sin la guía de un profesional especializado. Se concluye que el consumo de complementos alimenticios es elevado, sin una adecuada orientación profesional, por parte de los asistentes al gimnasio. Por ello, vemos como fundamental el papel de los nutricionistas en los gimnasios, trabajando en conjunto con los profesionales de Educación Física, ya que están capacitados para prescribir y controlar el uso de suplementos, haciendo así su consumo efectivo y seguro para los practicantes de actividad física.

Palabras clave: Centros de acondicionamiento; Ejercicio Físico; Sustancias para mejorar el rendimiento; Complementos nutricionales.

\section{Introdução}

Atualmente muitas pessoas estão em busca de um corpo considerado perfeito como padrão de beleza e isso tem levado ao aumento do uso de suplementos alimentares pela possibilidade de obtenção de resultados em curto prazo (Carvalho et al., 2018). Esses suplementos são utilizados com vários propósitos, como o ganho de massa muscular, redução da gordura corporal, melhoria do desempenho esportivo, perda de peso, melhoria estética e até mesmo prevenção de doenças (Molin et al., 2019).

Em um estudo realizado por Fabrini et al. (2007), foram observadas as razões para utilização de suplementos dietéticos por frequentadores de academias. Dos entrevistados estudados, 34,7\% declararam utilizar suplementos dietéticos com o objetivo de ganhar massa muscular, 34,7\% com a finalidade de aumentar a energia e melhorar a performance, $18,3 \%$ com o objetivo de garantir a saúde, $8,2 \%$ compensar deficiências da alimentação, 4,1\% responderam como razão dessa utilização prevenir doenças.

Um dos fatores que contribuem para o consumo abusivo desses suplementos e o uso inadequado dos mesmos é a ausência de uma legislação específica, sendo dispensada a obrigatoriedade de prescrição médica ou de nutricionista (Cengiz et al., 2017). Um dos problemas associados ao uso indiscriminado é que muitos consumidores desconhecem que o consumo excessivo de certos nutrientes que compõem alguns desses suplementos, pode trazer riscos à saúde, como problemas circulatórios, cardíacos e renais, principalmente pelo uso daqueles voltados à hipertrofia (Macedo \& Ferreira, 2021).

A Agência Nacional de Vigilância Sanitária (ANVISA) adverte sobre o consumo de suplementos alimentares, uma vez que muitos são produzidos em países que possuem normas diferentes das que estão em vigor no Brasil, podendo assim conter substancias não permitidas na legislação brasileira. Além do mais, podem conter informações duvidosas nos rótulos e até mesmo ocasionar prejuízos graves à saúde dos consumidores: dependência, efeitos tóxicos no fígado, insuficiência renal, disfunções metabólicas, alterações cardíacas, alterações do sistema nervoso e, em alguns casos, até a morte. Assim sendo, o consumo de suplementos de modo inadequado pode gerar problemas de saúde (Brasil, 2013).

Outro fator que pode ser observado nas academias é que muitos praticantes de exercícios físicos fazem uso de quantidade exagerada de nutrientes de origem proteica. Druker \& Edelsburg (2017) ressaltam, porém, que benefício algum é relatado pela literatura científica quanto à ingestão excessiva de proteínas, já que as mesmas são transformadas em gorduras e armazenadas em depósitos subcutâneos, sob forma de triacilgliceróis no tecido adiposo. Esse excesso de proteínas pode sobrecarregar o fígado, que é o responsável pelo metabolismo de aminoácidos, podendo também afetar os rins, já que muitos produtos são excretados por via urinária.

Sabe-se que é indispensável a orientação de um profissional de nutrição para praticantes de atividade física que desejam fazer uso de suplementos alimentares, pois são os profissionais qualificados para prescreverem dietas para pessoas com necessidade de perda ponderal, tanto para os esportistas, quanto para praticantes de atividades físicas (Paoli \& Araújo, 
2019). Nesse sentido, Carvalho et al., (2018), destacam a importância do nutricionista dentro de academias de ginástica e em outros ambientes relacionados as práticas esportivas, uma vez que existem muitas dúvidas entre os praticantes a respeito do uso de suplementos alimentares.

Silva et al., (2014) relatam que o meio mais utilizado para obtenção de informação sobre o uso de suplementos alimentares por atletas e jovens frequentadores de academia é pela indicação de amigos e profissionais de Educação Física.

Todavia, na conjuntura atual, o que acontece é que parte dos instrutores de academias ou profissionais de Educação Física indicam alguns suplementos sem terem o conhecimento adequado e/ou autorização legal para isso (Soares et al., 2019). Nesse sentido, Schuler \& Rocha (2018) verificaram que acadêmicos do curso de bacharelado em Educação Física apresentam falta de conhecimento no que se refere à nutrição suplementar, o que contribui com as práticas de indicação de dietas e suplementos de maneira equivocada, mesmo não tendo respaldo de autorização legal para prescrição de dietas e/ou suplementos.

Portanto, este estudo teve como objetivo identificar a prevalência de consumo e determinar o perfil, o tipo de suplemento e a fonte de prescrição ou recomendação de suplementos alimentares em academia de um município de Minas Gerais (Paschoarelli et al., 2015).

\section{Metodologia}

Trata-se de um estudo de caráter quantitativo, descritivo e de corte transversal, realizado em academias de um município de Minas Gerais.

A amostra da pesquisa foi composta por praticantes matriculados nas academias, no qual aplicou-se os questionários em uma amostra aleatória de 430 praticantes de atividade física. O projeto foi desenvolvido após aprovação do Comitê de Ética em Pesquisa após aprovação do Comitê de Ética em Pesquisa e das academias (Protocolo CAAE: 78896117.77.0000.5108). Todos os participantes assinaram o Termo de Consentimento Livre e Esclarecido (TCLE). O estudo foi conduzido de acordo com o Código de Ética da Associação Médica Mundial (Declaração de Helsinque). O tamanho da amostra foi calculado tendo como base a população estimada do município, conforme o Instituto Brasileiro de Geografia e Estatística (IBGE) e com percentual de prática de atividade física de 45,6\%, dos quais 15,1\% praticam musculação e/ou ginástica na região Sudeste conforme o Diagnóstico Nacional do Esporte - DIESPORTE (Brasil, 2016). Dessa forma a população praticante de musculação e/ou ginástica estimada para o município foi de 3321 pessoas. Nessa população praticante de musculação foi calculada uma amostra considerando a prevalência de uso de suplementos alimentares de 50\%, um intervalo de confiança de $95 \%$ e um erro aceitável de $5 \%$, perfazendo o total de 344 . Ao resultado final foi adicionado $20 \%$ para perdas e reposições na amostra. Totalizando uma amostragem mínima de 413 praticantes de atividade física. O tamanho amostral final possibilitou a participação de todos aqueles que demonstraram interesse em responder ao questionário no momento de aplicação. O cálculo amostral foi realizado no módulo StatCalc no Epi Info 7.2

Os participantes forma abordados pelo pesquisador na entrada das academias, em diferentes dias e horários de forma aleatória até atingir o número de participantes determinado pelo cálculo estatístico. Questionários orientados pelos pesquisadores foram utilizados para coletar informações sociais, comportamentais e nutricionais como: idade, gênero, escolaridade, tipo e frequência da atividade, conhecimento sobre alimentação saudável e o uso de suplementos, tempo e frequência de consumo, tipo de suplemento e fonte de indicação Zamin \& Schimanoski (2010) e Goston (2008). Uma abordagem quantitativa foi utilizada para a análise dos dados. Após os participantes responderem aos questionários, os dados foram digitados no Excel e analisados quanto à normalidade por meio do teste de D"Agostino - Pearson no programa BioEstat 5.3 , sendo comparadas as medianas e postos entre os grupos de pessoas que usavam ou não suplementos por meio do teste de 
Mann- Whitney, no programa Epi Info 7.2. As diferenças entre proporções foram analisadas por meio do teste de qui-quadrado (X2) no programa Epi Info 7.2. O nível de significância utilizado para interpretação dos resultados foi de $\alpha=0,05$.

\section{Resultados}

O total de praticantes de atividades físicas entrevistados foi de 430 de ambos os sexos com idade entre 18 e 79 anos, sendo 50,47\% do sexo feminino. A amostra também foi dividida em dois grupos: usuários e não usuários de suplementos alimentares (Tabela 1). Os usuários corresponderam a 50,93\% dos praticantes de atividade física que participaram da pesquisa. Entre os usuários 66,21\% eram do sexo masculino e entre os não usuários 67,77\% do sexo feminino. Foi observada associação significativa entre o uso relatado de suplementos e o sexo, sendo maior entre indivíduos do sexo masculino (66,21\%) do que entre os do sexo feminino $(\mathrm{X} 2=50,992 ; \mathrm{p}<0,0001)$. Observou-se que a média da idade foi de 28,38 anos (Desvio padrão: \pm 9,53 anos) entre os usuários e 29,44 anos ( \pm 11,69 anos) anos entre os não usuários, não tendo sido observada diferença estatisticamente significativa (Mann-Whitney; $\mathrm{H}=0,0674 ; \mathrm{p}=0,7952$ ). A mediana apresentada foi tanto de 26 anos para os usuários quanto para os não usuários.

Tabela 1 - Distribuição da amostra segundo o sexo dos usuários e não usuário de suplementos alimentares praticantes de atividade física em academias de ginástica.

\begin{tabular}{lccccccc}
\hline & \multicolumn{2}{c}{ Usuário } & \multicolumn{2}{c}{ Não usuário } & \multicolumn{2}{c}{ Total } \\
\cline { 2 - 7 } & Sexo $^{a}$ & $\mathrm{~N}$ & $\%$ & $\mathrm{~N}$ & $\%$ & $\mathrm{~N}$ & $\%$ \\
\hline Femino & 74 & 33.79 & 143 & 67.77 & 217 & 50.47 \\
Maculino & 145 & 66.21 & 68 & 32.23 & 213 & 49.53 \\
Total & 219 & 100 & 211 & 100 & 430 & 100 \\
\hline
\end{tabular}

${ }^{a}$ Associação entre sexo e condição de uso. X2 = 50,992; $\mathrm{P}<0,001$.

Fonte: Dados da pesquisa (2020).

Em relação ao grau de formação, a maioria dos usuários de suplementos alimentares 73,97\% possuía algum grau de formação superior, enquanto entre os não usuários o valor encontrado foi de $62,55 \%$.

O peso médio informado pelos usuários de suplementos foi 73,2 $\mathrm{kg} \pm 13,4 \mathrm{~kg}$ o mínimo de 46,6 kg e máximo de $123,0 \mathrm{~kg}$ e o grupo dos não usuários obteve média de $67,2 \mathrm{~kg} \pm 13,12$ e o peso mínimo de 42,0 kg e máximo de $117,0 \mathrm{~kg}$. A estatura média informada pelos participantes foi de 1,72 $\mathrm{m} \pm 0,095$, mínima de 1,40 m e máxima de 1,98 $\mathrm{m}$ para o grupo dos usuários de suplementos alimentares, já para o grupo dos não usuários foi apresentado uma média de 1,66 m $\pm 0,89$, mínima de 1,50 e máxima de $1,92 \mathrm{~m}$.

Em relação ao uso de suplemento segundo a satisfação com peso, aquele que usam suplementos 50,23\% consideraram-se satisfeito com seu peso, já no grupo dos que não usam suplementos 40,28\% estavam satisfeitos com seu peso, sendo essa diferença significativa $(X 2=3,86 ; \mathrm{p}=0,0495)$.

No que refere-se ao tempo de prática de atividade física entre usuários e não usuários de suplementos alimentares houve predominância do número de pessoas que pratica atividades físicas há mais de um ano no grupo dos usuários de suplementos alimentares $n=108$ e menos de três meses no grupo dos não usuários $n=88$. Foi observada tendência crescente e significativa de uso conforme o tempo de prática de atividade física (X2 de tendência = 27,05; $\mathrm{p}<0,0001)$.

Quanto aos principais objetivos da prática de atividade física (Gráfico 1), 182 indivíduos relataram que a motivação para o uso de suplementos foi melhorar a saúde e 185 indivíduos que não usam suplementos relataram o mesmo objetivo. Observou-se também que o número de usuários de suplementos que buscam a hipertrofia n=106 é mais que duas vezes o número daqueles que não usam suplementos e buscam a hipertrofia $n=46$, sendo essa diferença estatisticamente significativa $(\mathrm{X} 2=33,2735 ; \mathrm{p}<0,0001)$. Entre os que responderam praticar atividade física para fins de adquirir resistência predominaram 
pessoas que não usavam suplementos (X2 = 10,0707; $\mathrm{p}=0$,0018). Para os demais objetivos não foram observadas associações entre o uso ou não de suplementos. Os participantes da pesquisa tiveram a liberdade de responder mais de uma opção.

Gráfico 1 - Objetivo da prática de atividade física entre usuários e não usuário de suplementos alimentares em academia de ginástica.

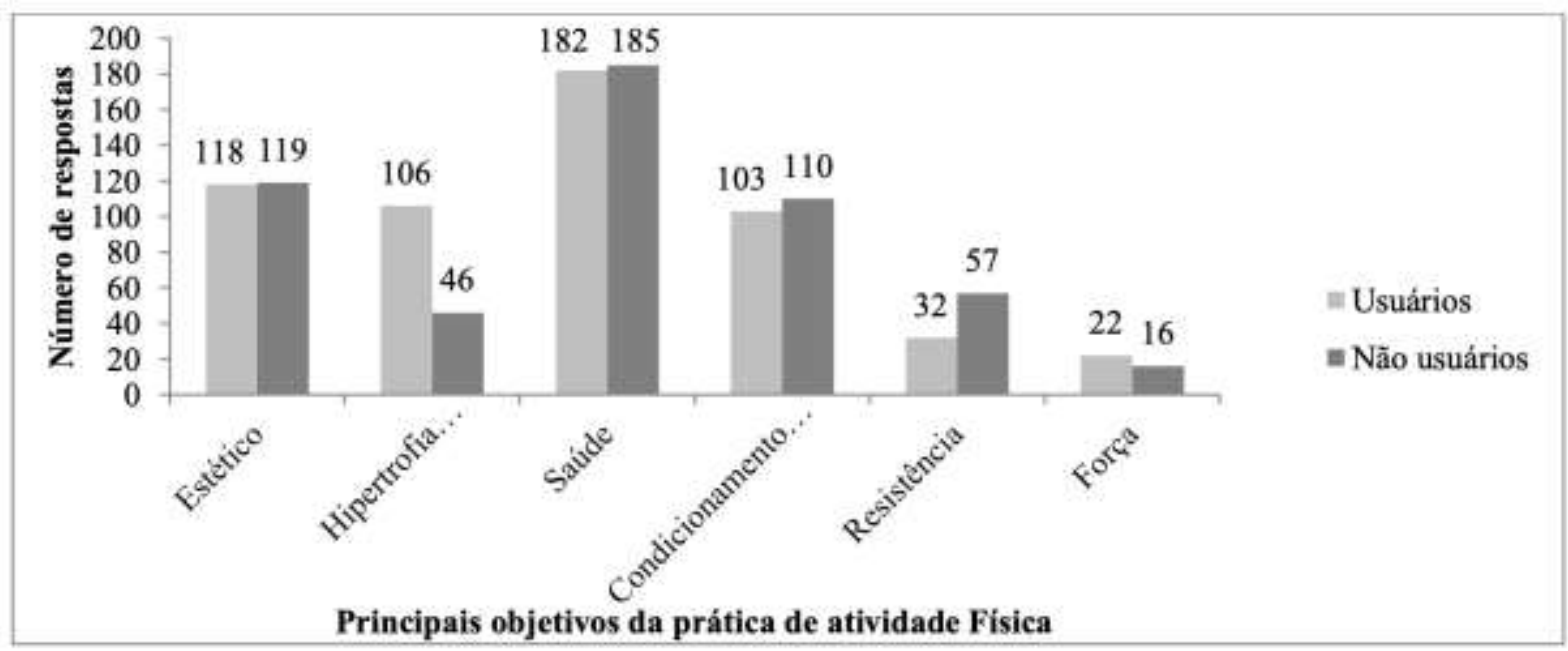

*O total em cada variável analisada é diferente do numero total de participantes $(\mathrm{N}=430)$, pois o mesmo participante poderia responder mais de uma alternativa.

Fonte: Dados da pesquisa (2020).

Sobre o posicionamento dos participantes da pesquisa em relação aos suplementos alimentares, 80,37\% dos usuários e $25,59 \%$ dos não usuários relataram que compreendem sobre o assunto. Os três suplementos mais consumidos pelos praticantes foram os ricos em proteínas $(42,56 \%)$, a creatina $(20,7 \%)$ e os aminoácidos $(18,84 \%)$ (Gráfico 2).

Gráfico 2 - Suplementos alimentares mais utilizados pelos praticantes de atividade física em academias.

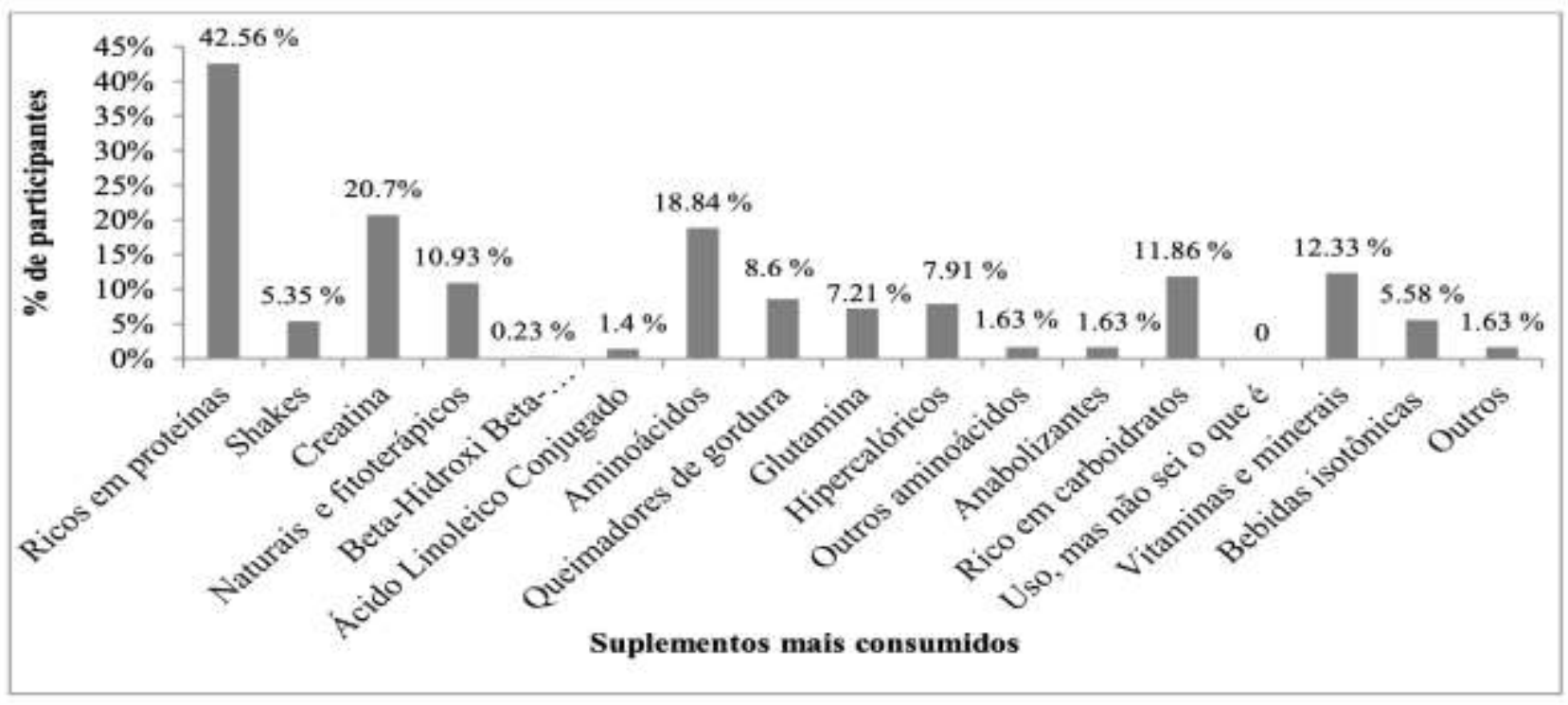

Outros: Termogênicos

* Os participantes poderia responder mais de uma opção.

Fonte: Dados da pesquisa (2020). 
Um maior número de indivíduos do sexo masculino relatou tomar preferencialmente suplementos ricos em proteínas $\mathrm{n}=127$ e creatina $\mathrm{n}=76$. Entre os indivíduos do sexo feminino, os suplementos mais consumidos foram às proteínas $n=56$ seguidos por naturais fitoterápicos $n=29$. Os objetivos mais alegados como uso dos suplementos alimentares foram o ganho de massa muscular $(40,93 \%)$, melhora da performance $(17,73 \%)$ e perda de peso $(15,35 \%)$.

Sobre frequência do consumo de suplementos alimentares, 44, 62\% dos usuários relataram consumir 4 a 5 vezes por semana. Observou-se que o resultado é coerente com a frequência da prática de atividade física, onde a maioria relatou praticar 4 a 5 vezes por semana.

Em relação ao tempo de uso dos suplementos alimentares, a maioria dos participantes $(68,45 \%)$ disseram fazer consumo de suplementos a menos de um ano e $(31,54 \%)$ relataram fazer uso entre um a dois anos.

Quando analisado os resultados adquiridos com o uso de suplementos alimentares, observou-se que parte dos usuários $(60,77 \%)$ relatou que obteve resultado desejado com o uso de suplementos alimentares, já $(6,92 \%)$ não tiveram resultados desejados, $(31,54 \%)$ ainda não tiveram resultados e $(0,77 \%)$ não souberam informar se obtiveram alguma resultado.

No que refere-se as fontes de prescrição ou recomendação de suplementos alimentares, notou-se que em geral os participantes de atividade física, usuários de suplementos (70\%) fazem uso sem indicação no nutricionista ou médico (Gráfico 3). E desses mais da metade (64,62\% relataram que não fazem acompanhamento com profissional.

Gráfico 3 - Fontes de prescrição ou recomendação de suplementos alimentares para praticantes de atividades física em academias de ginástica.

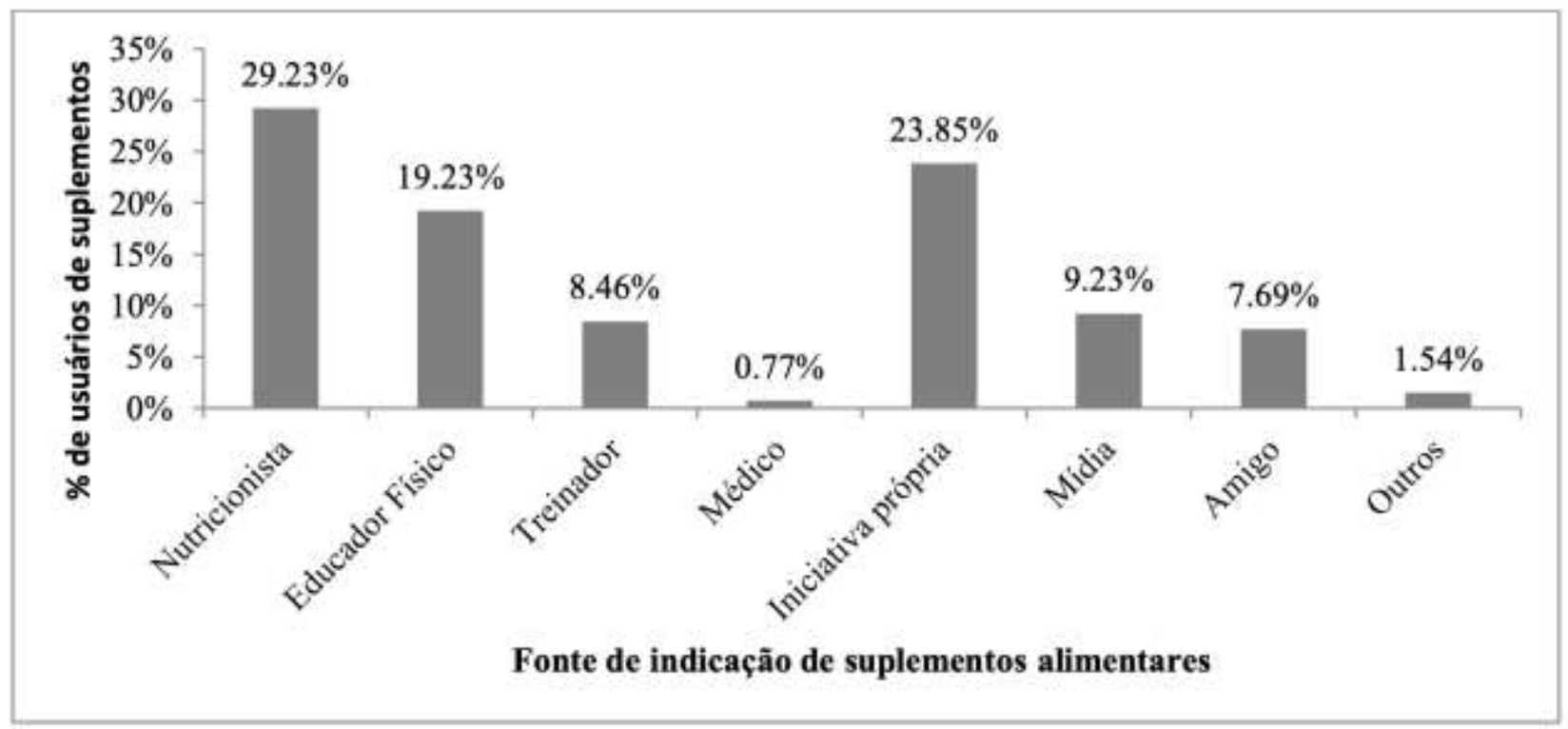

*Outros: Vendedores de loja de suplementos.

Fonte: Dados da pesquisa (2020).

\section{Discussão}

A busca por um corpo considerado ideal corrobora a procura por academias e consequentemente pelos suplementos alimentares, principalmente aqueles que prometem resultados rápidos (Maximiano \& Santos, 2017; Lima et al., 2019).

Atualmente, o consumo de suplementos tem se tornado excessivo por parte dos praticantes de atividade física (Maximiano \& Santos, 2017). A literatura científica tem salientado que os atletas consomem estes produtos em alta escala (Souza et al., 2020). 
A recomendação nutricional é fundamentada na Dietary Reference Intake (DRI), estabelecida conjuntamente pelos Estados Unidos e Canadá, tendo como referência a população destes países. Os valores de referência são usados na avaliação e planejamento de dietas, com a finalidade de promover a saúde, reduzir o risco de doenças e conter o consumo demasiado de algum nutriente por um indivíduo ou um grupo. As recomendações nutricionais da DRI abrange quatro conceitos para consumo de nutrientes: Necessidade média estimada (Estimated Average Requirements - EAR); Ingestão dietética recomendada (Recommended Dietary Allowance - RDA); Ingestão adequada (Adequate Intake - AI); Limite superior tolerável de ingestão (Tolerable Upper Intake Level - UL). O limite superior tolerável de ingestão surgiu como um alerta para conter consumo excessivo de micronutrientes devido ao progressivo uso de suplementos nutricionais e de alimentos fortificados (Chagas et al., 2016).

No presente estudo, verificou-se que dos 430 praticantes de atividade física entrevistados, 50,93\% consumiam suplemento alimentar, valor acima do encontrado por (Costa et al., 2013; Almeida et al., 2018).

Brito e Liberali (2012) ao investigarem o consumo de suplementos alimentares entre 137 praticantes de exercícios físicos na cidade de Vitória da Conquista (BA), constatou que 33,6\% da amostra era de usuários de suplementos alimentares.

Já Costa et al. (2013), em um estudo realizado em duas cidades do Vale do Aço (MG), verificou que dos 368 praticantes de atividade física entrevistados, 40,2\% consumiam algum tipo de suplemento alimentar. Assim como estudo de Pellegrini (2017) que identificou na cidade de São Carlos (SP), que 64\% relataram consumir ou já terem consumido suplementos alimentares, constatando assim, que o consumo de suplementos por praticantes de atividade física é elevado.

Neste estudo observou-se maior prevalência do uso de suplementos alimentares entre os indivíduos do sexo masculino (66,21\%). Dados semelhantes foram observados nos estudos de Araújo e Navarro (2008) e de Wagner (2011) em que os usuários de suplementos alimentares do sexo masculino representavam 70,0\% e 77,6\% da amostra, respectivamente. Outro estudo também demonstraram maior percentual entre os indivíduos do sexo masculino.

Confirmando que indivíduos do sexo masculino consomem mais suplementos que mulheres, Bezerra \& Macêdo (2013) e Pellegrini (2017), também observaram maior prevalência de indivíduos do sexo masculino 56,6\% e 78,5 respectivamente. Tal consumo pode ser explicado pelo motivo de que homens estão preocupados com aparência física musculosa, já as mulheres se preocupam em emagrecer (Pedrosa et al., 2019).

Observou-se que a média da idade foi de 28,3 \pm 9,53 entre os usuários e 29,4 \pm 11,69 entre os não usuários. Similar aos resultados encontrados no presente estudo, Bezerra e Macêdo (2013) verificou a média de idade dos entrevistados de 25,9 anos $\pm 5,3$ anos. Observação similar foi descrita por Domingues e Marins (2007), pois verificaram que 66\% dos indivíduos participantes da pesquisa estavam na faixa etária de 21 a 30 anos de idade. Sendo assim nota-se que parte dos indivíduos praticantes de atividade física nas academias são adultos jovens, perfil encontrado por Bezerra e Macêdo (2013). Para Hirschbruch et al., (2008), jovens fisicamente ativos são os usuários mais constantes de suplementos, uma vez que estes tendem a ceder mais à pressão da mídia, do que às orientações de profissionais qualificados sobre alimentação. Isso ocorre devido ao fato desses jovens se preocuparem mais com a aparência física do que com a qualidade de vida.

Em relação ao grau de formação, a maioria dos usuários de suplementos alimentares 73,97\% possuíam algum grau de formação superior, enquanto os não usuários o valor encontrado foi de 62,55\%. Resultado semelhante pode ser observado no estudo de Albino et al. (2009), composto por 120 frequentadores de academias de Lages (SC), onde o nível de escolaridade entre os praticantes de exercício físico e consumidores de suplementos, apresentou maiores percentuais para ensino superior completo equivalente a 39,09\%. Outro estudo que obteve resultado semelhante foi de Coluciuc et al. (2011) onde constatou que a maior porcentagem de indivíduos consumidores de suplemento em academias possuíam nível superior $(66,14 \%)$. Entretanto, no estudo realizado por Pellegrini (2017) 54,5\% dos entrevistados possuíam grau de escolaridade de nível médio completo. Semelhantemente, Zamin e Schimanoski (2010) relatou no seu estudo realizado em quatro academias de um 
município do noroeste do Rio Grande do Sul, que 55\% dos entrevistados possuíam ensino médio incompleto ou completo. Sendo assim, o resultado encontrado no nosso estudo vai de acordo com a literatura onde percebe-se que a escolaridade parece não influenciar na decisão em consumir suplementos.

O presente estudo apresentou que 50,23\% dos usuários de suplementos estão satisfeito com seu peso e 59,72\% dos não usuários relataram insatisfação com o peso atual. Para Schuler e Rocha (2018) a maioria dos indivíduos que praticam musculação possuem algum grau de insatisfação com sua imagem corporal e procuram desenvolver sua massa muscular de forma a apresentar uma silhueta mais forte e volumosa. Nesse sentido Macedo; Sousa; Fernandez (2017), relata que os principais motivos pelos quais as pessoas iniciam programas de atividade física e suplementação são a insatisfação com o próprio corpo ou mesmo pela imagem que se tem dele. Conforme Santo e Pereira (2017) indivíduos que se consideram fora do peso ideal têm como característica o descrédito da própria imagem e que estes passam por uma condição estigmatizada pela sociedade, favorecendo assim, sentimentos de insatisfação corporal. Estudos têm comprovado que a insatisfação corporal pode ser vista como sintoma de primeira ordem no desenvolvimento de comportamentos alimentares impróprios, podendo acarretar transtornos alimentares (Pradro \& Cezar, 2019). Além do mais, a prevalência de insatisfação corporal é vista como um problema de saúde pública, o qual carece de maior atenção em função de seus efeitos adversos, como depressão, baixa autoestima e transtornos alimentares (Mond et al., 2013).

Quando interrogados sobre o tempo de prática de atividade física, percebeu-se a predominância do número de pessoas que praticam atividades físicas há mais de um ano no grupo dos usuários de suplementos alimentares ( $\mathrm{n}=108)$ e menos de três meses no grupo dos não usuários ( $\mathrm{n}=88$ ). Semelhante aos dados do presente estudo Molin et al., (2019) e Costa et al. (2013), relataram que a maioria dos usuários de suplementos alimentares praticavam atividades físicas a mais de um ano. No estudo de Maximiano (2017), realizado com praticantes de atividade física em academias de ginástica da cidade de Sete Lagoas (MG), destacou que $80 \%$ dos frequentadores praticavam atividade física há mais de um ano. Já no estudo de Bezerra e Macêdo (2013), os resultados mostraram que mais de 70\% dos consumidores de suplementos praticam atividade física há mais de um ano. Segundo Paoli e Araújo (2019), as pessoas que praticam musculação por um período extenso estão sujeitos ao consumo de suplementos, com intuito de aumentar a resistência durante os treinos. Sobre a frequência semanal da prática de atividade física, os usuários de suplementos alimentares $(n=69)$ e não usuários $(n=72)$ disseram praticar atividade física 4 a 5 dias por semana. Essa mesma frequência foi observado por Costa et al. (2013) e Domingues e Marins (2007). Já Bezerra e Macêdo (2013) verificaram a frequência semanal de 3 a 5 dias. Sperandio et al., (2017) advertem que a atividade física é necessária para a saúde de todo indivíduo, sendo imprescindível torná-la um hábito, uma vez que atua na prevenção de alguns distúrbios tais como doenças cardiovasculares, obesidade, entre outros.

De acordo com o estudo, o tempo gasto para realização dos treinos diários foi de uma ou mais de uma hora tanto no grupo dos usuários quanto no grupo dos não usuários de suplementos. Resultados semelhantes foram localizados em um estudo realizado no município de Irati (PR) com 63 praticantes de musculação, onde todos praticam atividades físicas entre 1 a 2 horas por dia (Trog \& Teixeira, 2009). No estudo de Hirschbruch et al. (2008), a maioria dos participantes que consumiam suplementos praticava atividade física a mais de um ano permanecendo na academia por um tempo que variava de três a nove horas semanais. Para esses autores o consumo de suplementos está diretamente relacionado com o tempo de prática das atividades e a permanência nas academias, ou seja, quanto maior o consumo maior o tempo de atividades físicas.

Segundo Haskell et al., (2007) a American College of Sports Medicine (ACSM) e a American Heart Association (AHA), aconselham pelo menos 30 minutos diários de atividade física em intensidade moderada em cinco ou mais dias da semana, ou a prática de pelo menos 20 minutos diários de atividade física em intensidade vigorosa, em três ou mais dias na semana. 
O estudo revelou que parte dos entrevistados usuários de suplementos ( $\mathrm{n}=182)$ e os não usuários ( $\mathrm{n}=185)$ afirmaram que praticam atividade física com o objetivo de melhorar a saúde. Resultados similares encontram-se no estudo realizado por Bezerra e Macêdo (2013) onde mais de $60 \%$ dos entrevistados asseguraram que a praticam atividade física com o intuito de melhorar a saúde e estética. Semelhantemente, Pellegrini (2017) relatou em seu estudo que os entrevistados que consomem suplemento alimentar, tem como principal objetivo melhorar a qualidade de vida, bem-estar e saúde, seguido pela preocupação da hipertrofia e estética. Já outros estudos, apontam que o principal objetivo para a prática de atividade física é o ganho de massa muscular (Macedo \& Ferreira 2021; Cengiz et al., 2017; Costa et al., 2013). Esse mesmo objetivo também foi verificado no presente estudo, onde 106 usuários de suplementos declararam praticar atividade física com objetivo de hipertrofia. No entanto observou-se que o número de pessoas que buscam a hipertrofia e usam suplementos (n=106) é maior do que o número de pessoas que não usam suplementos e buscam a hipertrofia $(n=46)$. Esse resultado, mostra a percepção errônea dos praticantes de atividade física ao associarem que para o ganho de massa muscular deve haver impreterivelmente a ingestão de suplementos alimentares.

Em relação ao posicionamento dos participantes da pesquisa sobre alimentação e nutrição, 52,79\% consideram ter entendimento suficiente em relação à alimentação saudável, 29,7\% muito bom ou excelente e 18,14\% como insuficiente. Destes, $65,35 \%$ consideram a proteína como o nutriente que deve ter maior consumo diário e 0,47\% relatou que deve haver maior consumo de lipídeos diariamente. Diferentemente do estudo realizado por Zamim e Schimanoski (2010), onde os participantes responderam ter "conhecimento" excelente, muito bom e suficiente representando 15\%, $42 \%$ e $43 \%$ respectivamente. Dentre estes $67 \%$ relatam que alimentos fonte de carboidrato devem ter consumo superior aos demais.

O consumo de carboidratos correspondente a 60 a 70\% do aporte calórico diário atende à demanda de um treinamento esportivo. Para melhorar a recuperação muscular aconselha-se que o consumo de carboidratos esteja entre 5 e $8 \mathrm{~g} / \mathrm{kg}$ de peso/dia. Nas atividades de longa duração e/ou treinos intensos há necessidade de até $10 \mathrm{~g} / \mathrm{kg}$ de peso/dia para a apropriada recuperação do glicogênio muscular e/ou aumento da massa muscular (Hernandes \& Nahas, 2009).

Mas, ao contrário dos carboidratos, as proteínas são uma fonte pequena no fornecimento de energia, estima-se que contribuam com apenas 5 a 15\% do total calórico gasto. Mesmo assim, esse macronutriente é vital para promoção do processo de hipertrofia muscular (Zilch et al., 2012).

No que se refere ao consumo de lipídeos, o guia alimentar para a população brasileira, recomenda que o consumo de lipídios esteja entre 15\% e 30\% do valor energético total, recomendação semelhante à da (Who, 2003).

Sobre o seu posicionamento em relação aos suplementos alimentares, $80,37 \%$ dos usuários e 25,59\% dos não usuários relataram compreender sobre o assunto. Observa-se que 19,63\% dos usuários fazem uso sem mesmo ter o mínimo de informação sobre o assunto. Essa falta de informação pode levar ao consumo de suplementos de maneira incorreta. Nesse sentido, Maximiano (2017), descreve que a falta de informação sobre nutrição e suplementação esportiva pode induzir ao uso indevido de suplementos refletindo em prejuízos para a saúde.

Quanto aos suplementos mais consumidos, observa-se que um maior número de homens $n=127$ apresenta preferência pelos suplementos ricos em proteínas. Já entre as mulheres, os mais consumidos foram os ricos em proteínas n=56 e os naturais e fitoterápicos consumidos por 29 mulheres. Resultado semelhante pode ser visto no estudo de Goston (2009), quando foi observado que os homens consomem mais os suplementos ricos em proteínas $(47,5 \%)$ e carboidratos $(30,4 \%)$. Entre as mulheres, os suplementos mais consumidos foram os naturais e fitoterápicos $(40,5 \%)$, seguidos por vitaminas e minerais (27,0\%). Já no estudo de Costa et al. (2013) foi verificado que 20,0\% dos praticantes de atividade física consumiam suplementos ricos em proteínas, seguido da creatina $(13,8 \%)$ e do BCAA $(11,4 \%)$. Por sua vez, Brito e Liberali (2012) relataram que os suplementos mais utilizados em seu estudo foram Whey Protein e termogênicos, com igual percentual (24\%) entre ambos. Vários estudos confirmam que o consumo de proteína é predominante entre os praticantes de atividade física e a 
maioria deles consome com o objetivo do aumento de massa muscular (Bosquesi, Camisa, Santos, 2016; Sperandioet al., 2017; Pedrosa et al., 2019). Todavia, não há evidencias que garantam que o uso demasiado de proteína vá aumentar o ganho de massa muscular (Almeida et al., 2018). Para Maximiano (2017), os praticantes que treinam com elevadas sobrecargas tem a necessidade aumentada no consumo de proteínas, porém esta necessidade pode ser alcançada pela alimentação.

Em relação à frequência do consumo de suplementos alimentares, 44,62\% dos usuários relataram consumir 4 a 5 vezes por semana. Observou-se que o resultado é coerente com a frequência da prática de atividade física, pois a maioria relatou praticar 4 a 5 vezes por semana. O estudo de Goston (2009) relatou que 73,4\% dos usuários de suplementos praticavam exercícios de três a cinco vezes por semana, e consumiam os suplementos alimentares com a frequência maior ou igual a cinco vezes por semana. Já no estudo de Maximiano (2017), 4,8\% dos participantes relataram usar somente uma vez na semana, $47,6 \%$ faziam uso de duas a três vezes na semana enquanto 47,6\% afirmaram usar algum suplemento diariamente.

Referente ao tempo de uso de suplemento alimentares, $(68,45 \%)$ relatou fazer uso a menos de um ano e 31,54\% relataram fazer entre um a dois anos. Dados semelhantes foram encontrados por Bezerra e Macêdo (2013), o qual verificou que $50 \%$ dos participantes consumiam suplementos em período inferior a seis meses e mais de $30 \%$ consumiam a mais de um ano. Corroborando com os resultados, Zamim e Schimanoski (2010) revelou em seu estudo que apenas $28 \%$ dos participantes apresentaram tempo de consumo maior que um ano.

Quanto ao resultado desejado com o uso do suplemento alimentar, parte dos usuários (60,77\%), relatou que obtiveram resultado desejado e 39,23\% não tiveram, ou não sabem se tiveram resultado desejado. Resultado similar pode ser observado no grupo dos praticantes que usaram e não usam mais suplementos alimentares, onde 31,46\% informou não ter obtido resultado esperado durante o período de consumo.

Todavia, no estudo de Borges (2016) identificou que 53,8\% dos indivíduos relataram não ter alcançado o objetivo pretendido com a suplementação. De acordo com os dados do presente estudo e os dados encontrados na literatura, podemos considerar que parte dos usuários de suplementos não atinge os resultados desejados.

No que diz respeito à fonte de indicação, notou-se que $82,02 \%$ dos que já usaram suplementos alimentares e 70\% que ainda usam, fazem ou fizeram uso sem indicação de um profissional especializado. Dentre os que ainda usam suplementos $(64,62 \%)$ relataram que não fazem acompanhamento com um profissional. Segundo Soares et al., (2019) o consumo de suplementos alimentares precisa ser acompanhado por profissionais capacitados para tanto, e não podem ser utilizados cronicamente, pois podem alterar os efeitos desejados.

Em alguns estudos, a fonte de indicação mais citada foi a do grupo dos instrutores, professores de Educação Física, treinadores (Pellegrini et al., 2017; Paoli \& Araújo, 2019, Macedo \& Ferreira, 2021). Em um estudo realizado por Santos (2013), com 59 indivíduos de ambos os sexos, frequentadores de 3 academias em bairros nobres de Recife (PE), verificou- se que a fonte de indicação mais citada foi a do grupo dos amigos com 37\%, seguido por instrutores, professores e treinadores de exercício físico $27 \%$. De acordo com os resultados do estudo e os dados encontrados na literatura, observa-se que parte dos usuários de suplementos não fazem uso com orientação de um profissional especializado. Conforme Pedrosa et al., (2019), o nutricionista é o profissional que detém o conhecimento técnico, sendo capaz de orientar os praticantes de atividade física, na escolha por suplementos adequados ao tipo de atividade desenvolvida. Nesse sentido, a resolução Conselho Federal de Nutrição n. 390/2006 (CFN, 2006), regulamenta a prescrição dietética de suplementos nutricionais como responsabilidade do profissional nutricionista.

Carvalho (2018) afirmam que o uso impróprio de suplementos, sem orientação e acima das necessidades diárias, pode causar problemas renais e hepáticos. Esses mesmos autores alertam ainda que o excesso de proteína pode ser retido na forma de gordura ao invés de auxiliar na hipertrofia e que o uso de alguns suplementos como termogênicos e hormônios também 
podem comprometer o sistema cardiovascular, sistema nervoso e até mesmo no funcionamento da glândula tireoide, podendo desencadear doenças e até mesmo levar a óbito.

\section{Conclusão}

O consumo de suplementos alimentares por frequentadores de academia nesse estudo é expressivo. A maioria pratica atividades físicas há mais de um ano e consome suplementos por iniciativa própria ou por influências de treinadores e professores de Educação Física. Observou-se haver uma insatisfação muito elevada em relação ao peso corporal. Essa insatisfação pode estar ligada ao fato de que sociedade contemporânea impõe um padrão de beleza onde o indivíduo precisa ter um corpo atlético para ser considerado belo, o qual é cotidianamente disseminado pela mídia.

Observou-se também que é elevado o consumo de suplementos protéicos, bem como uma alta ingestão de proteínas com objetivo de ganhar massa muscular para moldar o corpo. A musculação foi à atividade física predominante tanto entre usuários de suplementos quanto não usuários, sendo que parece estar relacionada com uma preocupação com a estética e desempenho físico. Assim, pode perceber que a busca pelo corpo perfeito e pela força faz com que os indivíduos procurem suplementos e/ou substâncias para serem aceitos por uma sociedade altamente presente. Sendo assim, faz-se necessário a ampliação de informações e educação preventiva para os jovens, a fim de evitar o uso inadequado de suplementos alimentares bem como outras substâncias que podem ser nocivas ao corpo e à mente.

O consumo de suplementos alimentares é um tema que merece ser observado com maior atenção, pois existe uma facilidade muito grande em adquirir esses suplementos bem como há um leque de possibilidades quanto ao seu uso, que pode ser desde a área terapêutica ou simplesmente como alimentos ou repositores destes.

Perante o alto consumo e dos vários suplementos alimentares encontrados no presente estudo, é bastante preocupante sob a perspectiva nutricional o esclarecimento sobre os efeitos do uso indiscriminado dessas substâncias bem como a importância de regulamentações mais específicas para comercialização de tais produtos a respeito da sua eficiência e segurança.

Como possibilidades para novas pesquisas, sugere-se uma invesigação das necessidades educacionais dos professores de Educação Física em suplementação alimentares: desenvolvimento, implementação e avaiação de um curso. A análise poderá fornecer um panorama das dificuldades e necessidades dos Educadores Físicos, além de intrumentalização sobre a importância, perigos e cuidados na indicação e consumo de suplementos alimentares.

\section{Referências}

Albino, C. S., Campos, P. E. \& Martins, R. L. (2009). Avaliação do consumo de suplementos nutricionais em academias de Lages, SC. Revista Digital, 14(134), 1-12.

Almeida, S. G., de Almeida, A. G., dos Santos, A. L., \& Silva, M. L. (2018). A Influência de uma Rede Social nos Padrões de Alimentação de Usuários e Profissionais de Saúde Seguidores de Perfis Fitness. Ensaios e Ciência C Biológicas Agrárias e da Saúde, 22(3), 194-200.

Araújo, M. F. \& Navarro, F. (2008). Consumo de suplementos nutricionais por alunos de uma academia de ginástica, Linhares, Espírito Santo. Revista Brasileira de Nutrição Esportiva, 2(8), 46-54.

Bezerra, C. C. \& Macêdo, E. M. C. D. (2013). Consumo de suplementos a base de proteína e o conhecimento sobre alimentos proteicos por praticantes de musculação. Revista Brasileira de Nutrição Esportiva, 7(1), 224-232.

Borges, N. R., Silva, V. S. F. \& Rodrigues, V. D. (2016). Consumo de suplementos alimentares em academias de Montes Claros/MG. Revista Multitexto, 4(1), 54- 59 .

Bosquesi, R. M., Camisa, J., \& dos Santos, F. C. (2016). Avaliação dos teores de proteínas e lipídios em barras protéicas. Revista Brasileira de Nutrição Esportiva, 10(55), 24-30.

Brasil. Agência Nacional de Vigilância Sanitária. (2013). Relatório de atividades 2012, Anvisa, 104 p.

Brasil. Ministério do Esporte. (2016). Diagnóstico nacional do esporte - Diesporte. Caderno 2. O Perfil do Sujeito Praticante ou não de Esportes e Atividades Físicas da População Brasileira. 
Brito, D. S. \& Liberali, R. (2012). Perfil do consumo de suplemento nutricional por praticantes de exercício físico nas academias de Vitória da Conquista-BA. Revista Brasileira de Nutrição Esportiva, 6(31), 66-75.

Carvalho, J., Oliveira, B.N., Machado, A.A.N., Machado, E. P. \& Oliveira B. N. (2018). Uso de suplementos alimentar na musculação: revisão integrativa da literatura brasileira. Conexões, 16(2), 213-255.

Cengiz, F. P., Cemil, B. C., Emiroglu N., Bahali, A. G. \& Nahide, O. (2017). Acne located on the trunk, whey protein supplementation: Is there any association? Health Promot Perspect, 7(2), 106-108.

Chagas, B. L. F., do Nascimento, M. V. S., Barbosa, M. R., \& de Souza Gomes, L. P. (2016). Utilização indiscriminada de suplementos alimentares: causas e consequências. Caderno de Graduação-Ciências Biológicas e da Saúde-UNIT-SERGIPE, 3(2), 27-34.

Coluciuc, P. M., Macedo, Z. K., Navarro, F. \& Liberali, R. (2011). Uso de suplementos em duas academias do Paraná. Revista Brasileira de Nutrição Esportiva, 5(28), 298-304.

Conselho Federal De Nutrição. Resolução CFN N 390/2006. Regulamenta a prescrição dietética de suplementos nutricionais pelo nutricionista e dá outras providências. Brasília, 2006

Costa, D. C., Quintão, D. F. \& Rocha, N. C. A. (2013). Prevalência do uso de suplementos alimentares entre praticantes de atividade física em academias de duas cidades do vale do Aço/MG: Fatores associados. Revista Brasileira de Nutrição Esportiva, 7(41), 287-299.

Domingues, S. F. \& Marins, J. C. B. (2007). Utilização de recursos ergogênicos e suplementos alimentares por praticantes de musculação em Belo HorizonteMG. Fitness e Performance Journal, 6(4), 218-226.

Druker, I. \& Edelsburg, A. G. (2017). Identifying and assessing views among physically- active adult gym members in Israel on dietary supplements. Journal of the International Society Of Sports Nutrition, 14(37), 1-10.

Fabrini, S., Hallak, A. \& Peluzio, M. C. G. (2007). Avaliação do consumo de suplementos nutricionais em academias da zona sul de Belo Horizonte, MG, Brasil. Revista Brasileira de Nutrição Esportiva, 1(2), 55-60.

Goston, J. L., Correira, M. I. \& Toulson, D. (2009). Suplementos nutricionais: histórico, classificação, legislação e uso em ambiente esportivo. Revista Nutrição em Pauta, 17(98), 01-07.

Haskell, W. L., Lee, I. M., Pate, R. R., Powell, K. E., Blair, S. N., Franklin, M. C. A., Heath, G. W., Thompson, P. D. \& Bauman, A. B. A. (2007). Physical activity and public health: updated recommendation for adults from the American College of Sports Medicine and the American Heart Association. Med Sci Sports Exerc, 39(1), 1423- 34.

Hernandes, A. J. \& Nahas, R. M. (2009). Modificações dietéticas, reposição hídrica, suplementos alimentares e drogas: comprovação de ação ergogênica e potenciais riscos para a saúde. Revista. Brasileira de Medicina do Esporte, 15(3), 2-12.

Hirschbruch, M.D., Fisberg, M. \& Mochizuki, L. (2008). Consumo de suplementos por jovens frequentadores de academias de ginástica em São Paulo. Revista Brasileira de Medicina do Esporte, 14(6), 539-543.

Lima, T. A. M., Mazzoni, J. R. B., Amaral Gonçalves, R., Pereira, L. L. V., \& de Godoy, M. F. (2019). Estudo da utilização de esteroides anabólicos androgênicos e suplementos alimentares por universitários em São José do Rio Preto-SP. RBNE-Revista Brasileira de Nutrição Esportiva, 13(79), 333-339.

Macedo, M. G. \& Ferreira, J. C. S. (2021). Os riscos para a saúde associados ao consumo de suplementos alimentares sem orientação nutricional. Research, Society and Development, 10(3), 1-9.

Macedo, T. S., Sousa, A. L. \& Fernandez, N. C. (2017). Suplementação e consumo alimentar em praticantes de musculação. Revista Brasileira de Nutrição Esportiva, 11(68), 974-985.

Maximiano, C. M. B. F., \& Santos, L. C. (2017). Consumo de suplementos por praticantes de atividade física em academias de ginásticas da cidade de Sete Lagoas-MG. Revista Brasileira de Nutrição Esportiva, 11(61), 93-101.

Molin, T. R. D., Leal, G. C., Müller, L. S., Muratt, D. T., Marcon, G. Z., Carvalho, L. M. D., \& Viana, C. (2019). Marco regulatório dos suplementos alimentares e o desafio à saúde pública. Revista de Saúde Pública, 53-90.

Mond, J., Mitchison, D., Latner, J., Hay, P.; Owen, C. \& Rodgers, B. (2013). Quality of life impairment associated with body dissatisfaction in a general population sample of women. BMC Public Health, 13(920), 1-11.

Paschoarelli, L. C., Medola, F. O. \& Bonfim, G. H. C. (2015).Características qualitativas, quantitativas e quali-quantitativas de abordagens científicas: estudos de caso na subárea do Desing Ergonômico. Revista de Desing, Tecnologia e Sociedade, 2(1)65-78.

Paoli, V. P. \& de Araújo, M. C. (2019). Consumo e conhecimento de suplementos alimentares por atletas de alto rendimento de uma universidade da Grande Florianópolis. Revista Brasileira de Nutrição Esportiva, 13(82), 954-963.

Pellegrini, A.R., Nogiri, F.S. \& Barbosa, M.R. (2017). Consumo de suplementos nutricionais por praticantes de musculação da cidade de São Carlos-SP. Revista Brasileira de Nutrição Esportiva, 11(61), 59-73.

Pedrosa, F., de Souza, A. C. P. F., Leal, J. C., \& Marques-Oliveira, G. (2019). Efeitos da suplementação de creatina conciliada a cafeína sob a força de praticantes de musculação. Revista Brasileira de Nutrição Esportiva, 13(81), 739-748.

Prado, D. R. \& Cezar, T. C. M. (2019). Consumo de suplementos alimentares e o nível de conhecimento desses produtos por praticantes de musculação em academias na cidade de Cascavel-PR. FAG. Journal Of Health (FJH), 1(1), 203-211. 
Research, Society and Development, v. 10, n. 10, e374101018877, 2021

(CC BY 4.0) | ISSN 2525-3409 | DOI: http://dx.doi.org/10.33448/rsd-v10i10.18877

Santos, E. A. \& Pereira, F. B. (2017). Conhecimento sobre suplementos alimentares entre praticantes de exercício físico. Revista Brasileira de Nutrição Esportiva, 11(62), 134-140.

Santos, H. V. D., Oliveira, C. C. P., Freitas. A. K. C. \& Navarro, A. C. (2013). Consumo de suplementos alimentares por praticantes de exercício físico em academias de bairros nobres da cidade de Recife. Revista Brasileira de Nutrição Esportiva, 7(1), 1-8.

Schuler, A. C. \& Rocha, R. E. R. (2018). Fatores associados à utilização de suplementos alimentares por universitários. Revista Brasileira de Nutrição Esportiva, 12(73), 590-597.

Silva, W. V., Silva M, I. A. G., Toscano, L. T., Oliveira, K. H. D., Lacerda, L. M. \& Silva, A. S. (2014). Supplementation prevalence anda adverse effects in physical exercise practitioners. Nutr Hosp, 29(1), 158-165.

Soares, J. P., da Costa, A. C. P., de Araújo Costa, G., de Carvalho, L. M. F., \& Landim, L. A. D. S. R. (2019). Conhecimento nutricional e uso de suplementos alimentares por frequentadores de academias de uma capital do nordeste. Nutrição Brasil, 18(2), 95-101.

Souza, W. C., Roza, I., Smolarek, A. D. C., \& Mascarenhas, L. P. G. (2020). Suplementos Alimentares: Qual O Conhecimento Entre Adolescentes? Revista Eletrônica Nacional de Educação Física, 10(15), 66-74.

Sperandio, B. B., da Silva, L. D. S., Domingues, S. F., Ferreira, E. F., \& de Oliveira, R. A. R. (2017). Consumo de suplementos alimentares e recursos ergogênicos por mulheres praticantes de musculação em Ubá-MG. Revista Brasileira de Nutrição Esportiva, 11(62), 209-218.

Trog, S. D. \& Teixeira, E. (2009). Uso de suplemento alimentar com proteínas e aminoácidos por praticantes de musculação do município de Irati-PR. Revista Cinergis, 10(1), 43-53.

Wagner, M. (2011). Avaliação do uso de suplementos nutricionais e outros recursos ergogênicos por praticantes de musculação em academias de um bairro de Florianópolis-SC. Revista Brasileira de Nutrição Esportiva, 5(26), 130-134.

World Health Organization. (2003). Diet, nutrition and the prevention of chronic diseases. WHO Technical Report Series 916. Geneva.

Zamin, T. V. \& Schimanoski, V. M. (2010) Avaliação de hábitos alimentares saudáveis e uso de suplementos alimentares entre frequentadores de academias. Revista Brasileira de Nutrição Esportiva, 4(23), 410-419.

ZilchI, M. C, Soares, B. M., Bennemann, G. D., Sanches, F. L. F., Cavazzotto, T. G. \& Santos S E. F. (2012). Analise da ingestão de proteínas e suplementação por praticantes de musculação nas academias centrais da cidade de Guarapuava-PR. Revista Brasileira de Nutrição Esportiva, 6(35), 381-388. 